\begin{tabular}{|c|c|c|}
\hline & Int.J.Curr.Microbiol.App.Sci (2021) 10(08): 682-691 & \\
\hline & $\begin{array}{l}\text { International Journal of Current Microbiology and Applied Sciences } \\
\text { ISSN: 2319-7706 Volume } \mathbf{1 0} \text { Number } 08 \mathbf{( 2 0 2 1 )} \\
\text { Journal homepage: http://www.ijcmas.com }\end{array}$ & 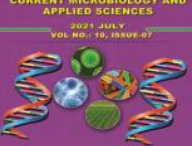 \\
\hline $\begin{array}{l}\text { EXCELLENT } \\
\text { PUBLISHERS }\end{array}$ & & wiww.jicmas.com \\
\hline
\end{tabular}

Original Research Article

https://doi.org/10.20546/ijcmas.2021.1008.077

\title{
Impact of Land Use on Soil Physico-Chemical Properties under Subtropical Condition
}

\author{
Girdhari Lal Jakhar, Peeyush Sharma*, Vikas Abrol and Vikas Sharma \\ Department of Soil Science, Sher-e-Kashmir University of Agriculture Science and \\ Technology, Jammu, Jammu and Kashmir, India \\ *Corresponding author
}

\section{A B S T R A C T}

Keywords

Land use systems,

Nutrient status, Soil physical properties, Soil mapping

Article Info

Accepted:

20 July 2021

Available Online:

10 August 2021
The present study was conducted to explore the variability in soil physical (bulk density, porosity, available water content, maximum water holding capacity) and chemical properties (soil organic carbon, available N, P, K, S and Zn) under different land use systems. The results showed that soil of different land use systems was found slightly acidic to neutral (6.6-7.2 $\mathrm{pH})$ in nature. The mean values of soil physical properties BD, porosity, AWRC, MWHC varied from 1.3 to $1.58 \mathrm{gcc}^{-1}, 40.25$ to $50.78 \%, 10.60$ to $20.40 \%$, and 29.58 to 40.94 , respectively. The SOC varied from 0.45 to $1.14 \%$. While the MWHC of the soils is non limiting in most part except some isolated patches. The mean values of available $\mathrm{N}, \mathrm{P}, \mathrm{K}, \mathrm{S}\left(\mathrm{kg} \mathrm{ha}^{-1}\right)$ ranged from 169.24 to $358.63,10.50$ to 26.73 , 101.19 to 359.81 , and 8.24 to 22.45 , respectively. Better soil physico chemical status was observed under forest soil over other land use. Results suggested that about $80 \%$ portion of the district were found to be deficient in zinc content with poor soil physical status which is harmful for root growth of the plants. This information can assist us for optimizing fertilizer and management practices which may need urgent attention.

\section{Introduction}

Continuous use of fertilizers and intensive farming system has become a major challenge for environment pollution and deterioration in soil health. To maintain the soil sustainability it is vital to improve soil physical, chemical and biological properties. The assumption of the sustainability of agricultural ecosystems also depends to a great extent on the maintenance and proper understanding of spatial distribution of soil physico-chemical properties that assist in site specific nutrient management (Geissen et al., 2009 and Wondowosen and Sheleme, 2011). To assess the suitable indicators, changes in soil physical, chemical and biological properties in relation to plant growth are of prime 
importance. Soil organic carbon (SOC) is a key indicator as it affects the other indicators such as bulk density, water content, porosity, nutrient retention and microbial population (Alvarez and Alvarez, 2000; Koutika et al., 2002; Jakhar et al., 2019). However, different land-uses and management practices affect its dynamics and composition (Stevenson, 1994; Abrol et al., 2019).

The predominantly hilly area $(86 \%)$ and $14 \%$ plain tract of Shiwalik Himalayan Region (SHR) of India suffers low crop productivity due to soil nutrient deficiencies and low water retention capacity (Bhattacharyya, 2016). Long term application of imbalanced nutrients, increased crop yield through high yielding varieties and intensive cultivation could lead to secondary and micronutrients deficiency (Shukla et al., 2015). Monitoring changes in soil physico-chemical properties is a challenge due to excessive and indiscriminate use of fertilizers, fragmented fields and heavy rainfall in Shiwalik Himalayan Region. Knowledge about physicochemical status of soil in different land use systems plays a vital role in enhancing production and productivity of the agricultural sectors on sustainable basis. However, practically oriented basic information on the up to date status of soil physico-chemical properties in the study area remains poorly understood. Therefore, this study was conducted with specific objectives to assess and explore the status of soil physico-chemical characteristics of five different land use systems of representative area of Udhampur district of Jammu and Kashmir.

\section{Materials and Methods}

The study area lies under the sub-tropical zone of foothills of Shawalik ( $32^{\circ} 34^{\prime}$ to $39^{\circ} 30^{\prime} \mathrm{N}$ and $74^{\circ} 16^{\prime}$ to $75^{\circ} 38^{\prime} \mathrm{E}$ ) (Fig 1). Out of approximately $2380 \mathrm{~km}^{2}$ area, the forest areas is $960.58 \mathrm{~km}^{2}$, land put to non-agriculture uses is 24516 hectare, barren and uncultivated land is 43700 hectare, permanent pasture and other grazing land is 5572 hectare, land other tree crops groves not included area in net sown area is 9576 hectare, cultivated land uses 14106 hectare, fallow land and other than current fallows is 320 hectare, current fallows 12391 hectare, gross sown area is 81494 hectare, net sown area is 44853 hectare, and net irrigated area is 7803 hectare.

Soil surface $(0-15 \mathrm{~cm})$ samples were collected by random manner from each site across whole of the district with the help of global positioning systems (GPS). The physical and chemical properties of soil were analyzed in laboratory includes particle size distribution, $\mathrm{pH}, \mathrm{EC}$, organic carbon content, bulk density, available water retention capacity, porosity, maximum water holding capacity, available nitrogen, available phosphorus, available sulphur and DTPA extractable Zn. Soil $\mathrm{pH}$ and EC was determined by potentiometric method (Jackson, 1973). Bulk density was measured by core method. Soil porosity was measured by keen box method (Keen and Raczkowski, H. 1921). SOC was measured by Walkley and Black (1934) method. Hydrometer method was used to measure the soil texture (Bouyoucos, 1962). The available N, P and K were determined by standard methods (Subbiah, and Asija, 1956; Olsen et al., 1954; Jackson 1973, respectively). The variability in soil properties were described using discriptive statistics such as mean, median, minimum, maximum, standard deviation, skewness and kurtosis.

\section{Results and Discussion}

\section{Soils basic and physical properties}

Soils of different land use systems have neutral reaction, with a mean $\mathrm{pH}$ range of 6.6 to 7.2 (Fig 2a). The lowest $\mathrm{pH}$ was found under forest soils followed by pasture shows 
the presence of high organic matter and leaching of basic cations due to heavy rainfall (Islam and Weil, 2000). The electrical conductivity of all soils of different land use systems was within the safe limit below 1 $\mathrm{dSm}^{-1}$ (Fig 2b). The forest and pasture land has lower EC than the other land use systems while the highest was in wasteland. Abbasi and Rassol (2005) explained that heavy rainfall caused accumulation of soluble salts in hilly area. The predominant texture class of the study area was sandy loam in texture (Table 1). Clay content was highest in soils of forest land, followed by those under pasture, horticulture and agriculture and least in wasteland (Fig. 3). The results are conformity with the findings of Gupta et al., (2010). The mean bulk density was generally higher in wasteland $\left(1.58 \mathrm{gcc}^{-1}\right)$ followed by agriculture, horticulture, pasture and lowest was in forest (Fig 5a). The soils of forest and pasture lands had higher values of porosity as compared to those of wasteland and cultivated lands (Fig 5b). MWHC and AWRC vary among the different land use and highest was in forest followed by pasture and the lowest was in wasteland. The large part of the area having soil BD, AWRC and porosity in the range of $1.40-1.63 \mathrm{gcc}^{-1}, \quad 10-20 \%$ and $32-47 \%$, respectively which affect the plant root growth (Fig. 10) because of low organic carbon, high sand content soil erosion (Gupta et al., 2010). Higher mean value of MWHC and porosity was found under forest land and pasture land use system followed by soils of agriculture, horticulture and wasteland (Fig 6) it's may be ascribed to presence of higher organic matter and clay fractions that leads to high porosity and permeability (Emadi et al., 2008). These findings are consistent with Sharma and Qahar 1989 and Gupta et al., 2010. Hajabbasi et al., (1997) reported similar findings. Hassan and Majumder (1990) has also reported that cultivated soils were considerably lower in silt and slightly lower in clay content than the adjacent soils under forest, most likely as result of preferential removal of silt by accelerated water erosion during the monsoon months (Emadi et al., 2008). The maps showed (fig 10) that the most of the part of the study area having poor physical status of the soil as the BD, AWRC and porosity were found affecting the root growth of the plants. While the MWHC of the soils is non limiting in most part except some isolated patches.

\section{Soil chemical properties}

The highest mean SOC was observed in forest $(1.14 \%)$ followed by pasture $(0.95 \%)$ and lowest was in wasteland (0.45\%) (Fig 7). Uncovered surface in arable soils resulted in poor carbon and other nutrients content (Basu \& Behera, 1993). The mean value of available nitrogen was low in wasteland, agriculture, horticulture and medium in forest (358.63 $\mathrm{kgha}^{-1}$ ) and pasture lands (309.07 $\mathrm{kgha}^{-1}$ ), respectively (Fig 8 a). Available phosphorus was medium in all land use types except wasteland soils where the nutrient concentration was low (Table 4, Fig 8b). The mean concentration of potassium was highest in agriculture and horticulture; medium in forest and pasture while lowest in wasteland (Fig 8c). The $S$ concentration was low in all land use systems (Fig 8d). Available $\mathrm{N}$ in soils of almost whole of the district is below 280 $\mathrm{kg} / \mathrm{ha}$ i. e it is in low category due to the high leaching losses of nitrate ions during rainfall periods. Variability in soil nutrient status revealed that organic carbon, available $\mathrm{N}, \mathrm{P}, \mathrm{K}$ was medium in most part of the study area, however $\mathrm{Zn}$ and $\mathrm{S}$ were low (Fig 10). Forest areas of the district has higher amount of available $\mathrm{N}$ than rest areas it's may be due the strong positively correlation between available $\mathrm{N}$ and organic carbon. Available $\mathrm{P}$ in soils of the entire district ranged from medium to high because of incorporation of phosphate containing fertilizers in these areas. 
Table.1 Soil textural classes under different landuse systems

\begin{tabular}{|c|c|}
\hline Type of land use systems & Textural Class \\
\hline Agriculture & Sandy Loam to Clay Loam \\
\hline Horticulture & Sandy Loam \\
\hline Forest & Sandy Loam to Loam \\
\hline Pasture & Sandy Loam to Loam \\
\hline Westland & Sandy Loam \\
\hline
\end{tabular}

Table.2 Correlation among soil properties

\begin{tabular}{|c|c|c|c|}
\hline Model & Regression equation & $\mathbf{R}^{\mathbf{2}}(\%)$ & F-values \\
\hline${ }_{1}$ st & $\mathrm{OC}=3.595^{* *}-1.994^{* *} \mathrm{BD}$ & 60.40 & $374.58^{* *}$ \\
\hline${ }_{2}$ nd & $\mathrm{OC}=3.092^{*}-1.751^{* *} \mathrm{BD}+.009^{* *} \mathrm{AWRC}$ & 62.00 & $199.96^{* *}$ \\
\hline${ }_{3}$ rd & $\mathrm{OC}=2.330-1.758^{* *} \mathrm{BD}+.023^{* *} \mathrm{AWRC}+.009^{* *} \mathrm{Clay}$ & 64.60 & $148.23^{* *}$ \\
\hline
\end{tabular}

Fig.1 Location map of the study area
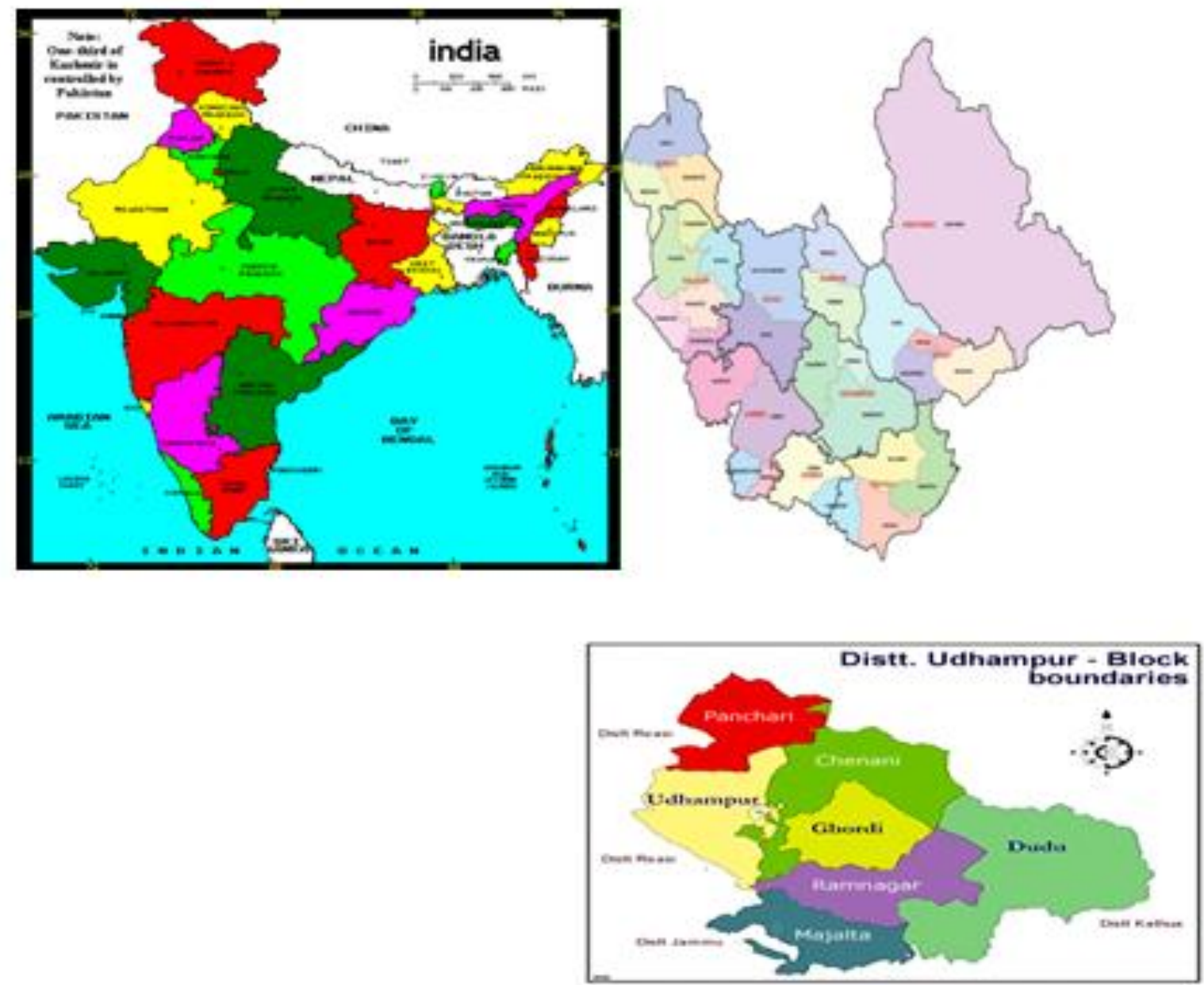
Fig.2 Mean value of soil $\mathrm{pH}$ and electrical conductivity under different land use systems

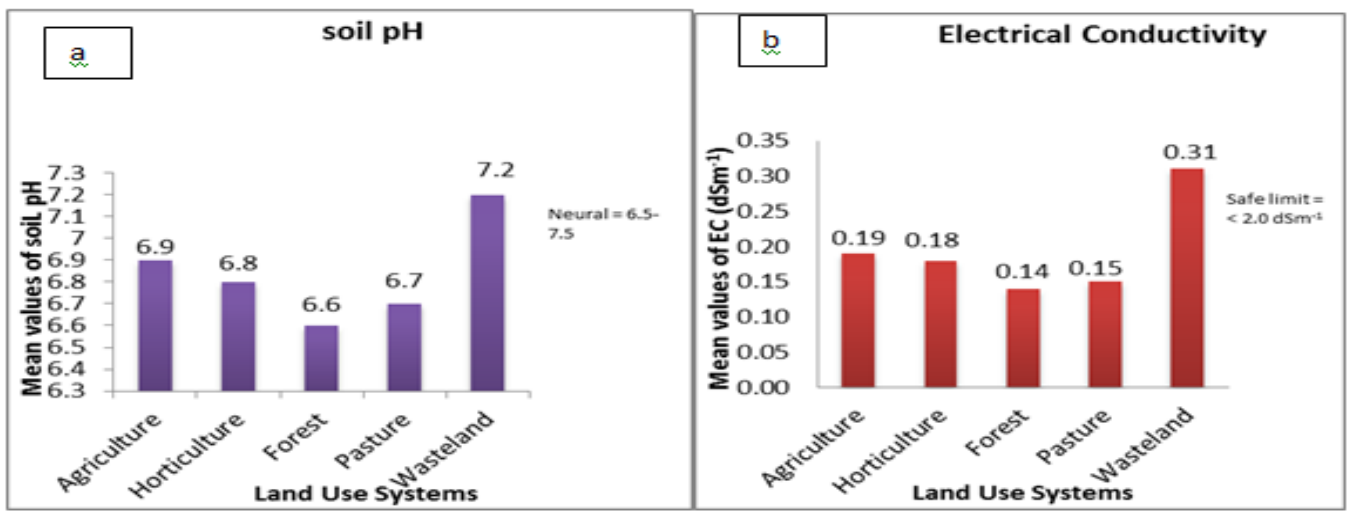

Fig.3 Mean value of soil clay (\%) and sand (\%) under different land use systems

(a)

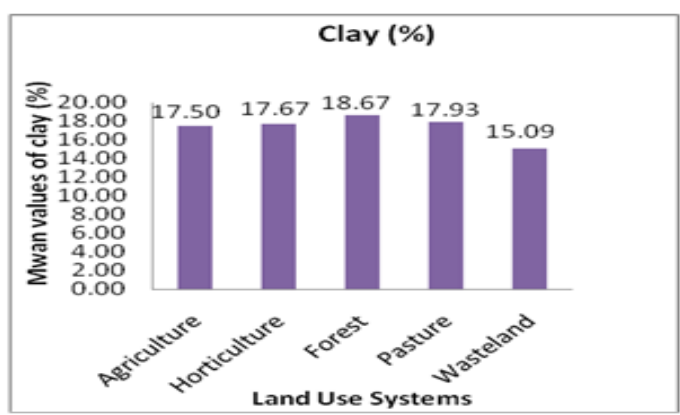

(b)

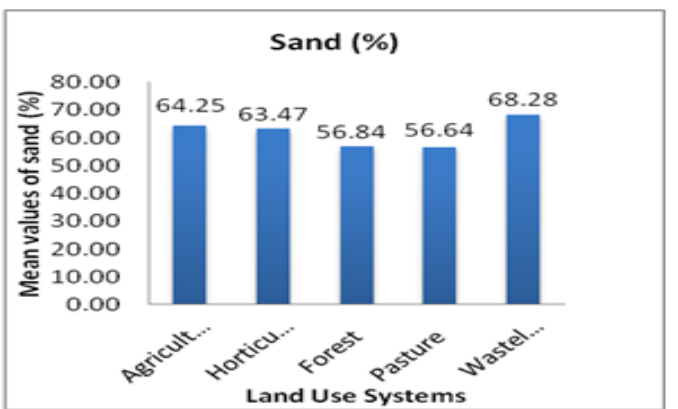

Fig.4 Mean value of soil silt (\%) under different land use systems

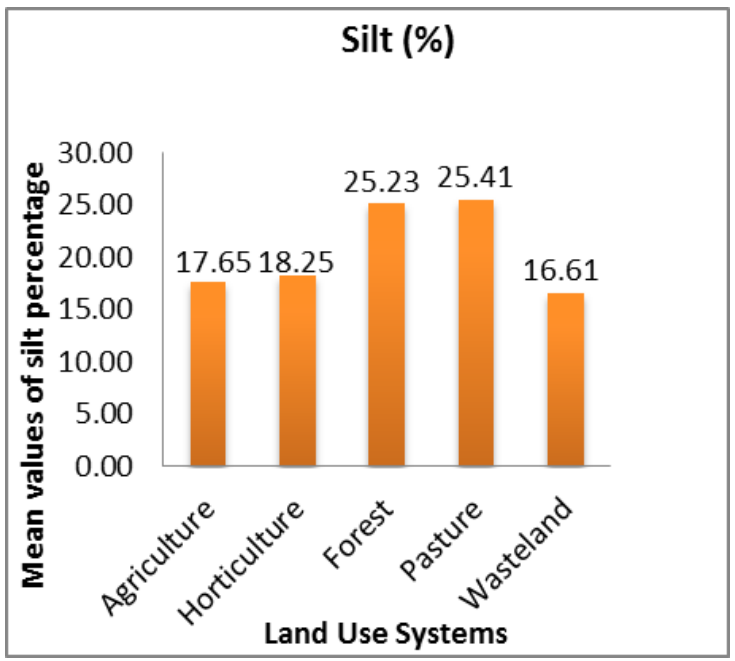


Fig.5 Mean value of soil bulk density and porosity under different land use systems

a

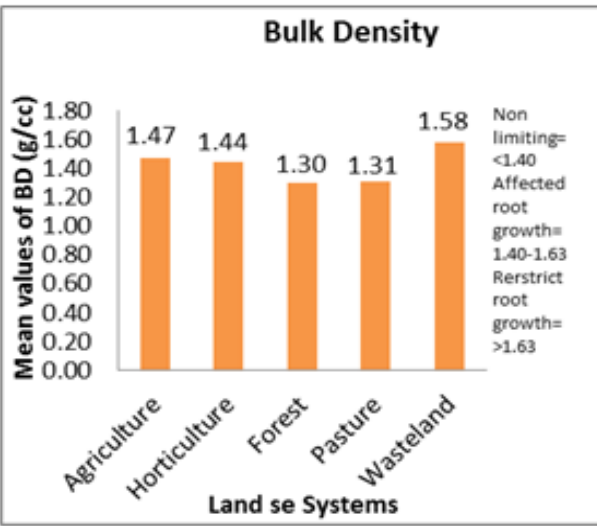

b

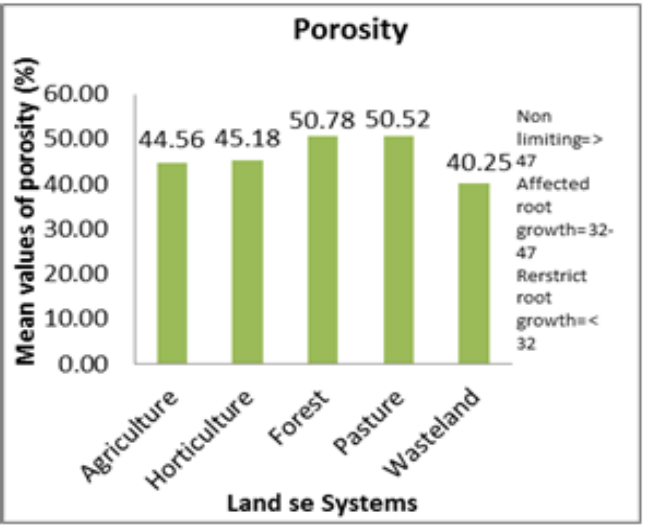

Fig.6 Mean value of soil maximum water retention capacity and available water retention capacity under different land use systems

a

b
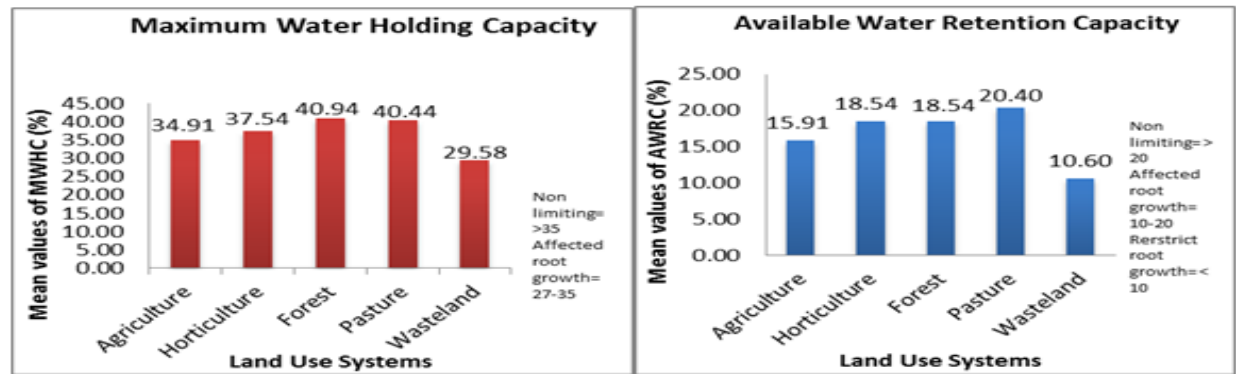

Fig.7 Mean value of soil organic carbon under different land use systems

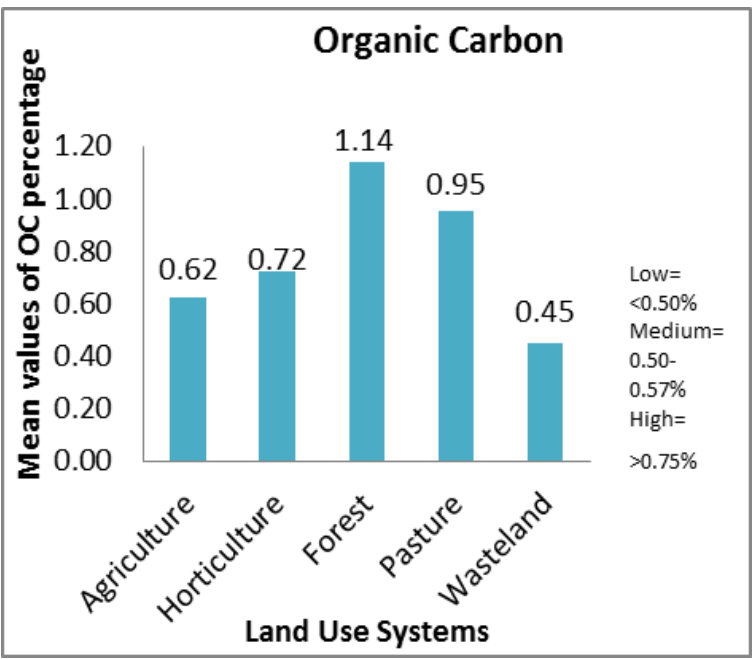


Fig.8 Mean value of soil available N, available $\mathrm{P}$, available $\mathrm{K}$ and available $\mathrm{S}$ under different land use systems

a

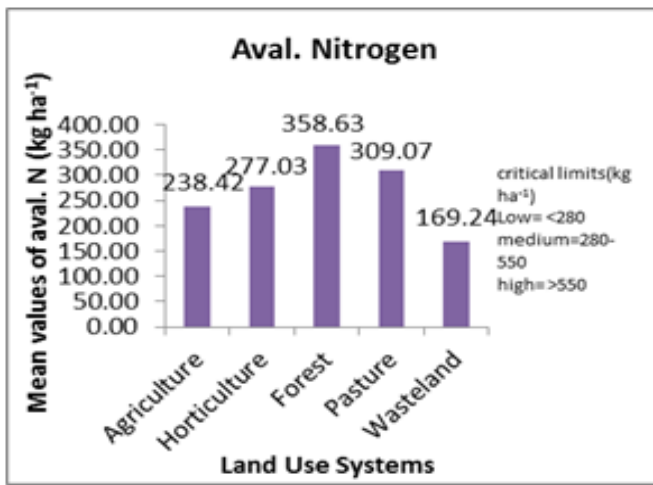

b

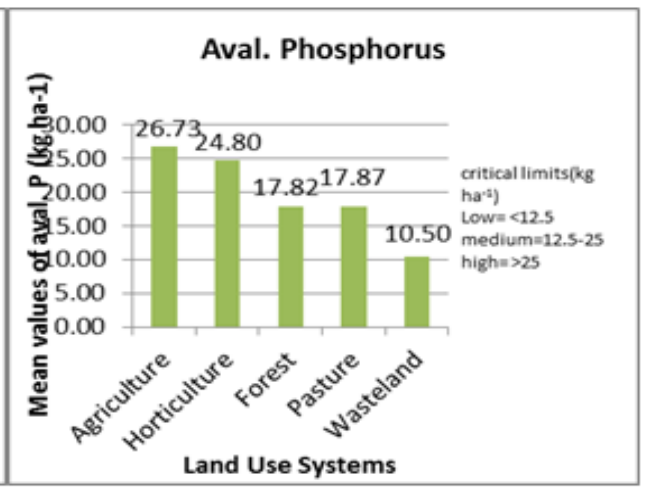

$\mathbf{C}$

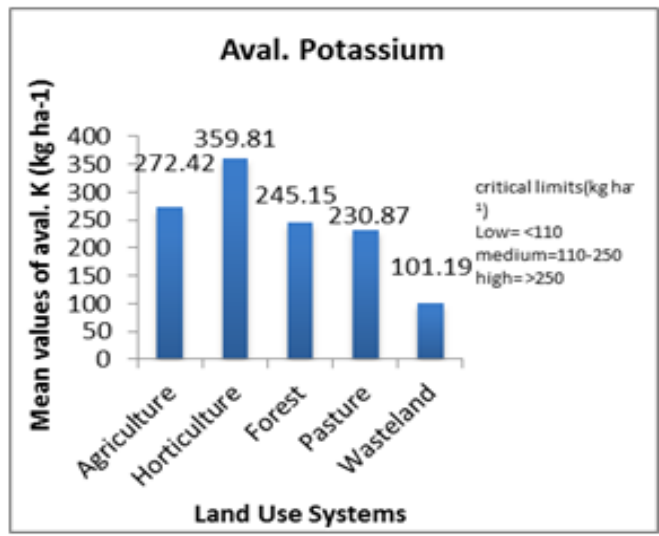

d

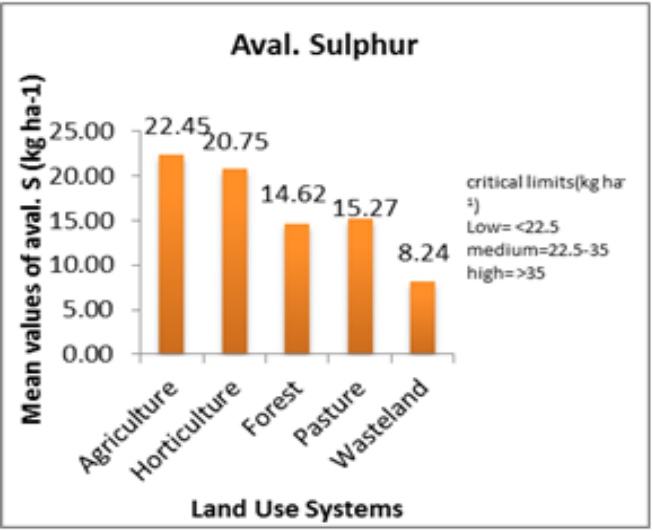

Fig.9 Mean value of DTPA Zn under different land use systems

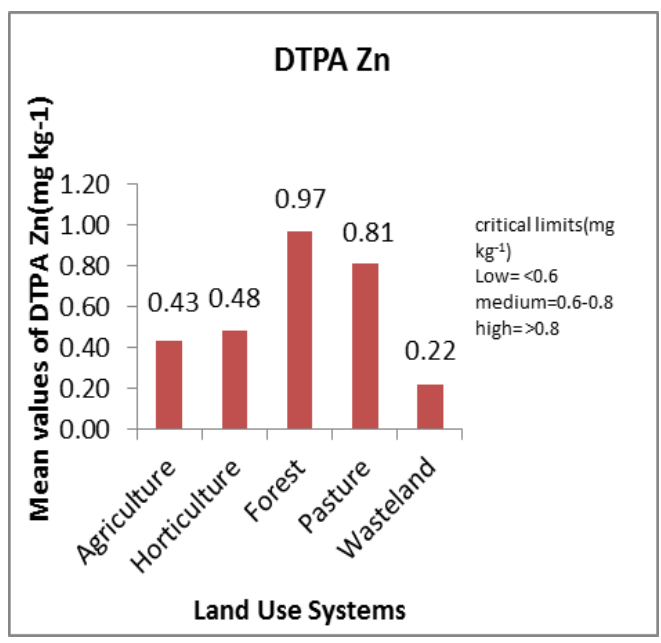


Fig.10 Spatial distribution maps of soil properties
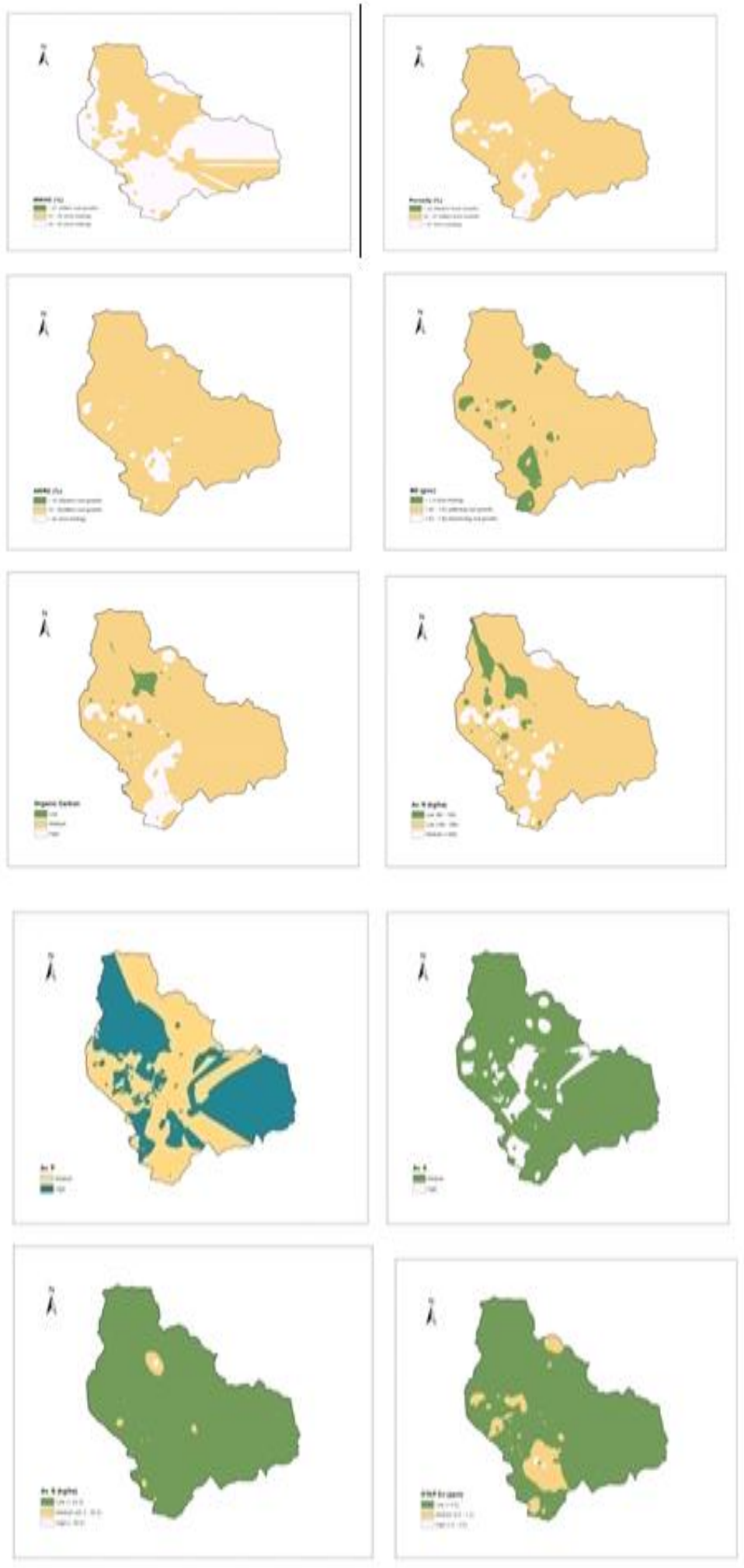
Available $\mathrm{K}$ was mostly in the medium range $(110$ to $280 \mathrm{~kg})$ in almost whole of the district because of dominance of potassium bearing minerals. The higher levels of available $\mathrm{P}$ and $\mathrm{K}$ in agriculture and horticulture land use systems was possibly due to addition of fertilizers (Fig 8, Fig 10). In forest land use system recycling of nutrients due to falling leaves of leguminous tree species was the possible reason for high available $\mathrm{N}, \mathrm{P}$ and $\mathrm{K}$ values. These results are in accordance with those of Gilly et al., (1997). Soils of about $80 \%$ portion of the district were found to be deficient in Zinc content ie it was below $<0.6$ ppm this might be due to low organic matter application coupled with no application of $\mathrm{Zn}$ in a rice-based system. Linear multiple regression of soil physical parameters (sand\%, silt \%, clay\%, BD, MWHC, AWRC and porosity) showed that only bulk density, AWRC and clay per cent affect the soil organic carbon significantly. In the first model of regression equation found that contribution of bulk density $\left(r^{2}=60.40\right.$ per cent $)$ was negatively significant. The model second shows that the value of $r^{2}$ was increased $(1.60$ per cent) along with available water retention capacity. With the addition of sand percentage distribution in model third the value of $r^{2}$ (64.60 per cent) was significantly increased (2.60 per cent). Results revealed that the overall soil physical health of Udhampur district was medium to good.

The forest is better in soil health as compared with the other land use system. Adoption of the proper management practices will be helpful in improving the soil health

\section{References}

Abbasi M K and Rasool G 2005. Effects of different land-use types on soil quality in the hilly areas of Rawalkot Azad Jammu and Kashmir. Acta Agriculturae Scandina vica. Section B.
Soil and Plant Sci, 55: 221-228.

Abrol V, Sharma R K, Sharma V, Sharma P, Sharma K R, and Sharma M.2019. Landuse impact on soil physical variability and erodibility in North Western subtropics of India. J. of Environmental Bio.4: 668-673.

Alvarez R and Alvarez C R.2000. Soil organic matter pools and their associations with carbon mineralization kinetics. Soil Sci. Society of America J. 64 (1): 184-189.

Basu S and behera N. 1993. The effect of tropical soil conservation on soil microbial biomass. Biol. and ferti. of soil, 6:6-3..

Bhattacharyya R, Gosh B N, Dogra P, Mishra P K, Santra P, Kumar S and Fullen M A.2016. Soil conservation issue in India. Sustainability 8: 565.

Bouyoucos G J.1962. Hydrometer method improved for making particle size analysis of soils. Agron. J. 54: 464465.

Emadi M, Mehdi E, Baghermejad H, and Saffari M. 2008. Effect of land use change in selected soils. Physical and chemical properties in North Highlands of Iran. J. of Applied Sci. 8: 496-501.

Geissen V, Scanchez-Hernandez R,. Kampichler C R A and HernandezDaumas S. 2009. Effects of land-use change on some properties of tropical soils-an example from southeast Mexico. Geoderma 151 (3-4):87-97.

Gilley J E, Doran J W, Karlenand D L. Kaspar T C.1997. Runoff, erosion, soil quality characteristics of a former Conservation Reserve Program site. J. of Soil Sci. and Water Conservation 52:189-093..

Gupta R D, Arora S, Gupta G D and Sumberia N M 2010. Soil physical variability in relation to soil erodibility under different land uses in foothills of 
Siwaliks in NW, India. Tropical ecology 51:183.

Hajabbasi M A, A. Jalalianand. Karimzadeh H R 1997. Deforestation effect on soil physical and chemical properties, Lord Egan, Iran. Plant and Soil 190: 301308.

Hassan M M and. Majumder A H 1990. Distribution of organic matter in some representative forest soils of Bangladesh. Agriculture. Indian Journal of Forestry 13: 281-287.

Islam K R and. Weil R R 2000. Land use effects on soil quality in a tropical forest ecosystem of Bangladesh. Indian J. of forestry $13: 281-287$.

Jackson M L 1973. Soil Chemical Analysis. Prentice Hall of India Pvt. Ltd., New Delhi, p. 498.

Jakhar G L, Sharm P, Sharma K R, Sharma V, Abrol V, Sharma $M$ and Sharma N 2019. Soil bulk density as a soil physical health indicator under different land use systems. J. of Soil and Water Conservation 4: 326-333.

Keen B A and Raczkowski H 1921. The relation between the clay content and certain physical properties of a soil. The j. of Agril. Sci. 11(4) :441-449.

Koutica L S, Sanginga N, Vanlauwe B and Weise S 2002. Chemical Properties and soil organic matter assessment under fallow systems in the forest margins benchmark. Soil Biology and Biochemistry 34: 757-765.

Olson, R A, Rhodes M B, and Dreier A F
1954. Available Phosphorus Status of Nebraska Soils in Relation to Series Classification, Time of Sampling and Method of Measurement Agron. J. 4: 175-180.

Sharma P D and, Qahar A Q 1989. Charaterization of some Outer Himalayan protected and eroded forest soils. J. of Ind. Soc. of Soil Sci..37:113-120.

Shukla, A K,. Srinivastava P C, Tiwari P K, Prakash C, Patra A K, Singh P and Pachuri S D 2015. Mapping current micronutrients deficiencies in soils of Uttrakhand for precise micronutrient management. Ind. J. of Fert., 11 :52-63.

Stevenson, F J 1994. Humus chemistry : genesis, compostion, reactions. John Wiley and Sons.

Subbiah B V and Asija G L 1956. A rapid procedure for the estimation of available nitogen in soils. Current Science, 25:259-260.

Walkley, A and Black, I. A 1934. Determining soil organic matter, and proposed modification of the chromic acid titration method. Soil Sci., 37(1) : 2938.

Wondsen, T and Sheleme B 2011. Identification of growth limiting nutrients in Alfisols: Soil Physicochemical properties, nutrient concentration and biomass yield of Maize. American Journals of Plant nutrition and Fertiliztion Technology 1:23-35.

\section{How to cite this article:}

Girdhari Lal Jakhar, Peeyush Sharma, Vikas Abrol and Vikas Sharma. 2021. Impact of Land Use on Soil Physico-Chemical Properties Under Subtropical Condition. Int.J.Curr.Microbiol.App.Sci. 10(08): 682-691. doi: https://doi.org/10.20546/ijcmas.2021.1008.077 